\title{
miR-101 inhibits glioma cell invasion via the downregulation of $\mathrm{COX}-2$
}

\author{
CHUNYANG MA*, CHUANYI ZHENG* ${ }^{*}$ ENQI BAI and KUN YANG \\ Department of Neurosurgery, The Affiliated Hospital of Hainan Medical College, Haikou, Hainan 570102, P.R. China
}

Received March 27, 2015; Accepted April 22, 2016

DOI: $10.3892 / \mathrm{ol} .2016 .4939$

\begin{abstract}
Glioma is the most common type of primary tumor of the central nervous system. The present study aimed to demonstrate the role of miR-101 and cyclooxygenase-2 (COX-2) in the initiation and development of glioma. The expression of miR-101 and COX-2 in normal and malignant human glial cells and tissues was determined by western blotting and quantitative polymerase chain reaction analysis. The role of miR-101 on COX-2 expression was evaluated by a dual-luciferase reporter assay. The effects of miR-101 and COX-2 in glioma cell proliferation and invasion was verified by CCK- 8 test and Transwell assays, respectively. The present study demonstrated that miR-101 expression was downregulated while COX-2 was upregulated in glioma tissues and cells. Furthermore, transfection of miR-101 significantly downregulated COX-2 expression in both U373 and U87 glioma cells. In addition, further experiments revealed that overexpression of miR-101 resulted in significant inhibition of the in vitro proliferation and migration of glioma cells, and the in vivo growth of established tumors. Direct downregulation of COX-2 by transfection with corresponding small interfering RNA also inhibited the proliferation and invasion of glioma cells. These results indicate that downregulation of miR-101 is involved in the initiation and development of glioma via COX-2 upregulation.
\end{abstract}

\section{Introduction}

Glioma is the most common primary tumor of the central nervous system with an annual incidence of 3-5 cases per 100,000 individuals, accounting for $\sim 46 \%$ of all intracranial tumors in the United States $(1,2)$. Glioma is the second leading cause of mortality in young cancer patients $(<34$ years of

Correspondence to: Mr. Kun Yang, Department of Neurosurgery, The Affiliated Hospital of Hainan Medical College, 31 Longhua Road, Haikou, Hainan 570102, P.R. China

E-mail: yangkundoc@163.com

*Contributed equally

Key words: miR-101, cyclooxygenase-2, glioma age) (2). High morbidity and mortality rates make glioma the fourth most fatal malignant cancer (3). Currently, the standard treatment for glioma is surgical resection followed by combined administration of radiation and adjuvant chemotherapy $(4,5)$. Despite current therapeutic efforts, the median survival time ( $\sim 14$ months) has not changed significantly in the past decades (6). The poor prognosis and low 5-year survival rate $(<10 \%)$ highlights the urgent requirement for the development of novel therapeutic methods against glioma $(2,7)$. At present, cancer treatment studies predominantly focus on molecular therapies, thus the identification of efficient targets is of great importance.

Cyclooxygenase-2 (COX-2) is an important enzyme that regulates the conversion of arachidonic acid to prostaglandin E2 (PGE2) (8). Previous studies have demonstrated that PGE2, which is produced normally by epithelial cells and at extremely high levels in a variety of malignant tumors, upregulates the activity of T-regulatory cells, which suppress immune function, resulting in tumor progression and poor disease outcome (8-11). Martín Sanz et al (12) revealed that as single molecule modification of COX-2 may induce tumorigenesis in COX-2 transgenic mice without other genetic modifications. Krzystyniak (13) reported that COX-2 upregulation affects both angiogenesis and the production of specific proteases that are critical for glioma cancer growth and metastasis (13). Based on these previous studies, the downregulation of COX-2/PGE2 signaling may present a promising and efficient method for the prevention and treatment of malignant tumors.

MicroRNAs (miRNAs) are small, non-coding RNAs ( 22 nucleotides in length) that mediate the post-transcriptional silencing of specific target mRNAs $(14,15)$. miRNAs are currently recognized as important regulators of various biological functions in a number of cellular processes, including cellular proliferation, differentiation, metabolism and apoptosis $(14,15)$. To date, $>400$ human miRNAs have been identified and $>1,000$ have been postulated to exist (16). It is hypothesized that $\leq 30 \%$ of human genes are regulated by miRNAs (17). Each miRNA regulates a variety of targeting genes, and an individual mRNA may be regulated by distinct miRNAs, giving rise to an extensive regulatory network $(15,18)$. A number of miRNAs, including miR-21, miR-221/222, miR-124 and miR-128, are aberrantly expressed in malignant gliomas and are considered to have important functions in determining the degree of malignancy (19-22). 
The present study determined the relative expressions and functions of miR-101 and COX-2 in glioma cells, as well as the regulatory roles between them, thus, providing novel possibilities for the prevention and treatment of glioma.

\section{Materials and methods}

Patients and specimens. Fresh-frozen human glioma tissues $(n=40)$ and matched distant normal tissues were obtained from patients who underwent radical surgery between January 1 and October 1, 2013, at the Affiliated Hospital of Hainan Medical College (Haikou, China). The patients included 24 men and 16 women, with a mean age of 51 years. None of these patients received radiotherapy or chemotherapy prior to surgical resection. All 40 cases were reviewed for histological subtype, differentiation and tumor stage (23). Written informed consent was obtained from all patients.

Cell culture. The human glioma cell lines U373-MG and U87-MG, and the normal human glial cell line C6, were obtained from the American Type Culture Collection (Manassas, VA, USA). Cells were cultured in Dulbecco's modified Eagle's medium (DMEM) (Gibco; Thermo Fisher Scientific, Inc., Waltham, MA, USA) supplemented with $10 \%$ bovine calf serum (Gibco; Thermo Fisher Scientific, Inc.) and maintained at $37^{\circ} \mathrm{C}$ in a humidified atmosphere of $5 \% \mathrm{CO}_{2}$.

Reverse transcription (RT)-quantitative polymerase chain reaction $(q P C R)$. Total RNA was extracted from malignant and normal tissues (which were soaked in formalin solution for $1 \mathrm{~h}$ and stored at $-80^{\circ} \mathrm{C}$ prior to use) and cells using Isogen reagent (Nippon Gene Co., Ltd., Toyama, Japan). Total RNA (3 $\mu \mathrm{g})$ was reverse-transcribed using MultiScribe Reverse Transcriptase (Applied Biosystems; Thermo Fisher Scientific, Inc.), according to the manufacturer's instructions. miR-101 and COX-2 mRNA expression levels were analyzed using TaqMan ${ }^{\circledR}$ Small RNA assays (Applied Biosystems; Thermo Fisher Scientific, Inc.) and a MiniOpticon Real-Time PCR System (Bio-Rad Laboratories, Inc., Hercules, CA, USA) according to the manufacturer's instructions. The PCR cycling conditions included initial denaturation at $95^{\circ} \mathrm{C}$ for $3 \mathrm{~min}$ followed by 40 cycles of $95^{\circ} \mathrm{C}$ denaturation for $12 \mathrm{sec}$ and $62^{\circ} \mathrm{C}$ annealing for $40 \mathrm{sec}$. Expression values were normalized against glyceraldehyde 3-phosphate dehydrogenase (GAPDH) mRNA expression levels by the $2^{-\Delta \Delta \mathrm{Cq}}$ methods. The oligonucleotide primer sequences of miR-101 and COX-2 are shown in Table I.

Western blot analysis. Cell or tissue lysates were separated by $10 \%$ sodium dodecyl sulfate-polyacrylamide gel electrophoresis and transferred to a polyvinylidene difluoride membrane (EMD Millipore, Darmstadt, Germany). The membrane was blocked with 5\% non-fat milk and incubated with rabbit primary antibodies against COX-2 (rabbit, anti-human, monoclonal; catalog no. 12282; 1:2,000 dilution) and GAPDH (rabbit, anti-human, monoclonal; catalog no. 5174; 1:3,000 dilution) (Cell Signaling Technology, Danvers, MA, USA) at $4^{\circ} \mathrm{C}$ overnight. After three washes with Tris-buffered saline containing $0.1 \%$ Tween-20, the membrane was incubated with corresponding horseradish peroxidase-conjugated secondary
Table I. Oligonucleotide primer sequences used for reverse transcription-polymerase chain reaction in the present study.

\begin{tabular}{lc}
\hline Oligonucleotide & Primer sequence (5'-3') \\
\hline $\begin{array}{l}\text { Cyclooxygenase-2 } \\
\text { Forward }\end{array}$ & \\
Reverse & GCACCCCGACATAGAGAGC \\
miR-101 & CTGCGGAGTGCAGTGTTCT \\
Forward & \\
Reverse & ACGGGCGAGCTACAGTACTGTG \\
\hline
\end{tabular}

Table II. miRNA sequence used for vector transfection.

\begin{tabular}{lc}
\hline miRNA & Sequence $\left(5^{\prime}-3^{\prime}\right)$ \\
\hline miR-101 & TGCCCTGGCTCAGTTATCACAGTGC \\
& TGATGCTGTCTATTCTAAAGGTACA \\
& GTACTGTGATAACTGAAGGATGGCA
\end{tabular}

miRNA, microRNA.

antibody (goat anti-rabbit IgG-horseradish peroxidase; catalog no. sc-2030; 1:3,000 dilution; Santa Cruz Biotechnology, Inc., Dallas, TX, USA) for $1 \mathrm{~h}$ at room temperature. Immunoreactive bands were visualized with a Pierce enhanced chemiluminescence system (Thermo Fisher Scientific, Inc.).

Vector construction. miRNA expression plasmids were constructed using the pRNAT-U6.1/Neo vector (GenScript, Piscataway, NJ, USA). The pre-miRNAs were synthesized (Table II) and cloned into the pRNAT-U6.1/Neo vector. The luciferase reporter vector was constructed using the pGL3-basic vector (Promega Corporation, Madison, WI, USA) and the 3'-untranslated region of COX-2 was amplified by RT-PCR. The COX-2 small interfering RNA (siRNA) was synthesized by Invitrogen (Thermo Fisher Scientific, Inc.).

Cell transfection. Cells were grown to $70-80 \%$ confluence and respectively transfected with miR-101 or mock vehicles using Lipofectamine 2000 (Invitrogen; Thermo Fisher Scientific, Inc.) according to the manufacturer's instructions. Cells transfected with miR-101 and mock vehicles were termed U373(87)/miR-101 and U373(87)/NC, respectively. After $48 \mathrm{~h}$, cells were harvested, and underwent limited dilution in a 96-well plate for the generation of individual clones. Three weeks later, the level of COX-2 mRNA in the cell clones transfected with miR-101 was analyzed by RT-qPCR.

Dual-luciferase reporter assay. A dual-luciferase assay was performed as described previously (24). Briefly, cells were seeded in a 24 -well plate at $\sim 80 \%$ confluence and transfected with miRNA expression vector, reporter vector and the pRL-TK control vector encoding Renilla luciferase (Biovector Science Lab, Inc., Beijing, China), using Invitrogen Lipofectamine 2000 according to the manufacturer's instructions. 
Following $24 \mathrm{~h}$ of transfection, cells were harvested, lysed by CyQuant ${ }^{\circledR}$ cell Lysis Buffer (Thermo Fisher Scientific, Inc.) and analyzed using the Dual-Luciferase Reporter Assay System kit (Promega Corporation). All experiments were performed in triplicate.

Cell proliferation assays. Cell proliferation was analyzed using Cell Counting Kit-8 (CCK-8; Dojindo Molecular Technologies, Inc., Rockville MD, USA) as previously described (25). Briefly, 3,000 cells/well were seeded in a 96-well plate. At daily time intervals (days 1-7), $10 \mu$ l CCK-8 was added to each well, followed by incubation for $2 \mathrm{~h}$ in the dark. The absorbance $(\mathrm{Ab})$ was recorded at a wavelength of $450 \mathrm{~nm}$ by a microplate reader (Thermo Multiskan MK3; Thermo Fisher Scientific, Inc.) and cell viability was calculated using the following equation: Cell viability $(\%)=\left[\left(\mathrm{Ab}_{\text {sample }}-\mathrm{A} \mathrm{b}_{\text {blank }}\right) /\left(\mathrm{Ab}_{\text {control }}-\mathrm{Ab}_{\text {blank }}\right)\right]$ x $100 \%$, (where $A b_{\text {sample }}, A b_{\text {control }}$ and $A b_{\text {blank }}$ are the $A b$ values of each sample, the cells cultured in culture medium without any additional substances and the culture medium without cells in wells, respectively).

Transwell assays. A cell migration assay was performed using 24-well Transwell plates as previously described (26). Briefly, the under surface of the membrane was coated with human fibronectin $(10 \mathrm{mg} / \mathrm{ml}$; Gene Operation, Ann Arbor, MI, USA) in phosphate-buffered saline at $37^{\circ} \mathrm{C}$ for $2 \mathrm{~h}$. The lower chamber was filled with $0.6 \mathrm{ml}$ DMEM supplemented with 10\% fetal bovine serum (Gibco; Thermo Fisher Scientific, Inc.). Prior to the experiment, cells were serum-starved overnight [DMEM plus $0.5 \%$ bovine serum albumin (BSA; Beyotime Biotechnology, Shanghai, China], then $1 \times 10^{6}$ cells in $0.1 \mathrm{ml}$ migration medium (DMEM plus $0.5 \% \mathrm{BSA}$ ) were added to the upper chamber. After incubation at $37^{\circ} \mathrm{C}$ for $12 \mathrm{~h}$, cells on the upper surface of the membrane were removed. The migrated cells that had attached to the lower surface were fixed in 10\% formalin and stained with a solution containing $1 \%$ crystal violet and $2 \%$ ethanol in $100 \mathrm{mmol} / \mathrm{l}$ borate buffer (pH, 9.0; Beyotime Biotechnology). The number of migrated cells on the lower surface of the membrane was counted under a light microscope.

In vivo tumor growth assays. Four-week-old female BALB/c nude mice (mean weight, $14.3 \mathrm{~g}$ ) were purchased from Dashuo Biotechnology Co., Ltd. (Chengdu, China) and raised in specific pathogen-free conditions at $26^{\circ} \mathrm{C}$. A total of $5 \times 10^{6}$ control and miR-101 overexpressing cells were injected subcutaneously into BALB/c nude mice (age, 6-8 weeks), respectively. The tumor size was measured in two perpendicular diameters with precision calipers and calculated using the following equation (25): Tumor volume $\left(\mathrm{mm}^{3}\right)=\left(\right.$ length $\mathrm{x}$ width $\left.{ }^{2}\right) / 2$. At the end of the experiments, all the mice were sacrificed by cervical vertebra dislocation.

Statistical analysis. The Student's $t$-test was performed to compare differences between two groups, whereas analysis of variance followed by Dunnett's multiple comparison test was used to compare more than two groups. Data are presented as mean \pm standard deviation. All data analyses were performed using SPSS version 10.0 (SPSS, Inc., Chicago, IL, USA). P $<0.05$ was considered to indicate a statistically significant difference.
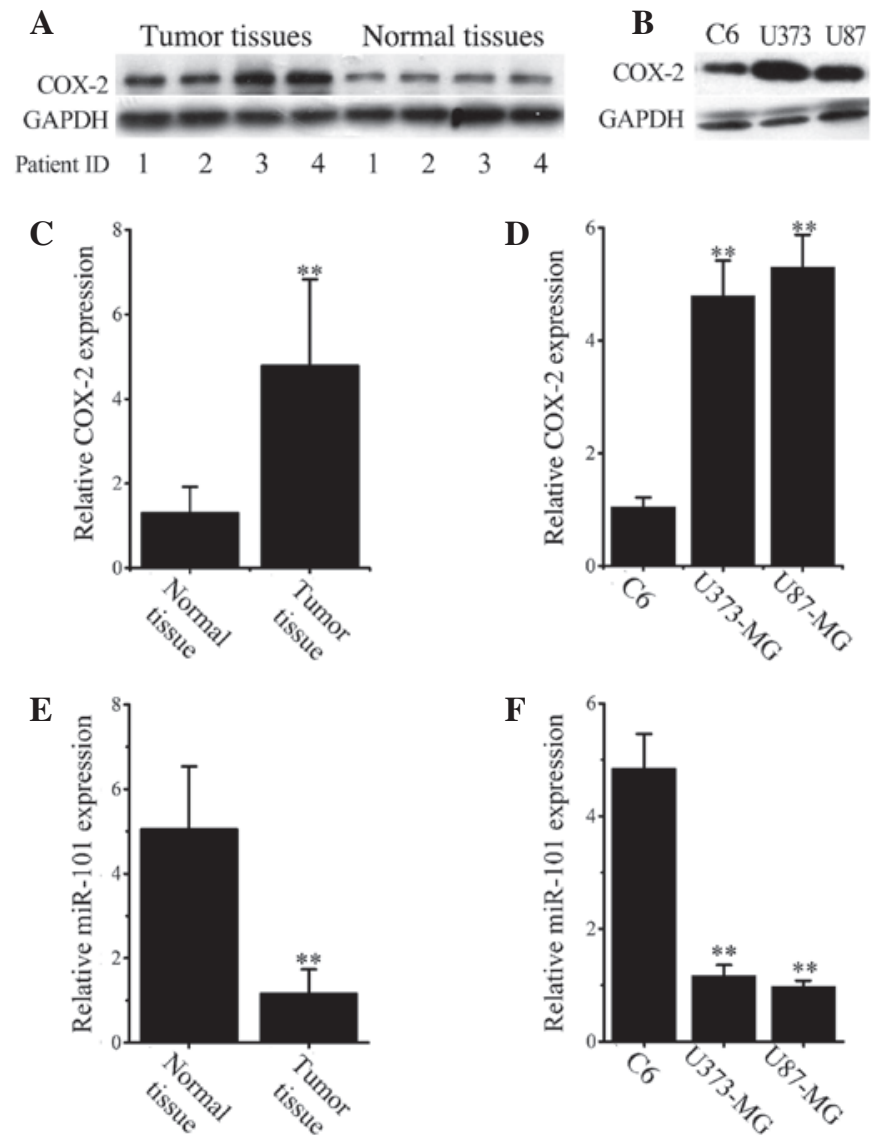

Figure 1. Upregulated COX-2 and downregulated miR-101 expression in human glioma tissues and cells. (A) Representative western blotting images for COX-2 in paired glioma and adjacent non-tumor tissues. (B) Western blotting analysis of COX-2 expression in C6, U373 and U87 cells. (C) Relative COX-2 mRNA expression was analyzed in (C) normal and malignant tissues and (D) normal (C6) and malignant (U373 and U87) cells by RT-qPCR. (E) Relative miR-101 expression levels in (E) normal and malignant tissues and (F) normal (C6) and malignant (U373 and U87) cells was analyzed by RT-qPCR analysis. Data are expressed as the mean \pm standard deviation. ${ }^{* *} \mathrm{P}<0.01$ vs. control. COX-2, cyclooxygenase-2; RT-qPCR, reverse transcription-quantitative polymerase chain reaction; GAPDH, glyceraldehyde 3-phosphate dehydrogenase.

A
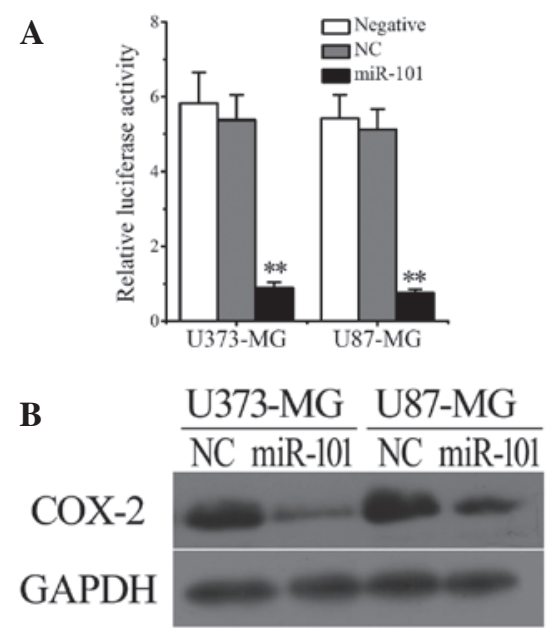

Figure 2. COX-2 may present a direct target of miR-101 in vitro. (A) Luciferase activity was significantly decreased following transfection with miR-101 but not NC in U373 and U87 cells. (B) Western blotting revealed that transfection with miR-101 markedly reduced cellular COX-2 expression in U373 and U87 cells. Data are presented as the mean \pm standard deviation $(n=3)$. ${ }^{* *} \mathrm{P}<0.01$ vs. control. COX-2, cyclooxygenase-2; GAPDH, glyceraldehyde 3 -phosphate dehydrogenase; NC, empty vector. 
A

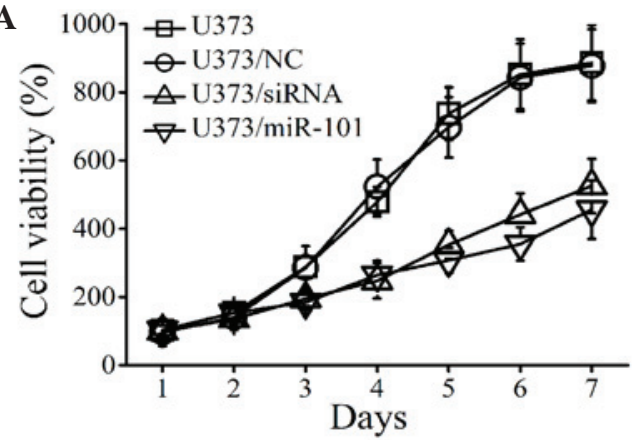

C

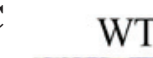

WT

$\frac{2}{5}$

\section{$12 \mathrm{~h}$}

$24 \mathrm{~h}$

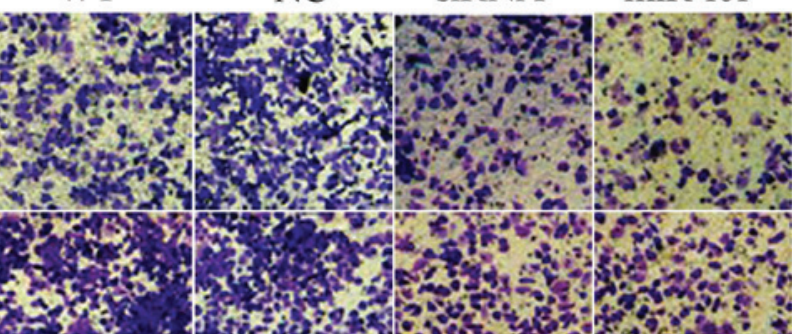

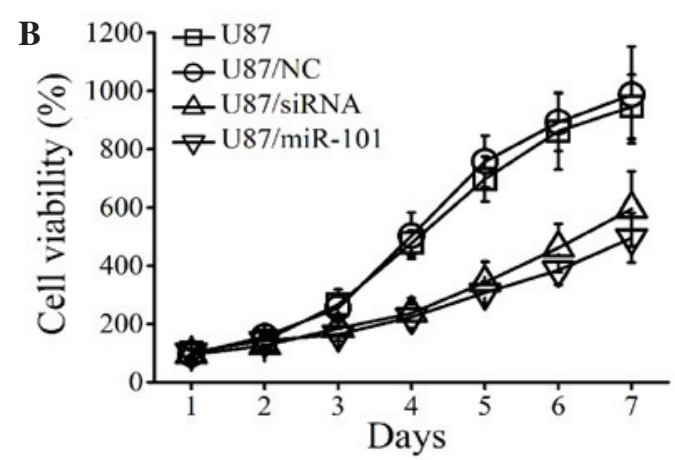

D

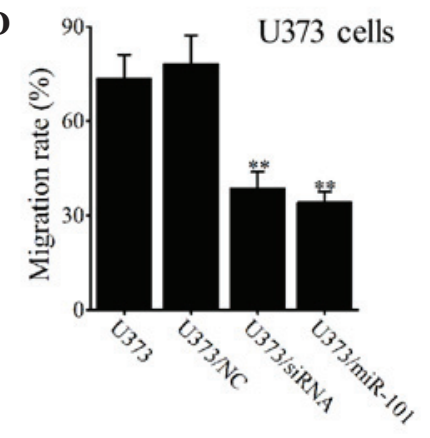

$\mathbf{E}$

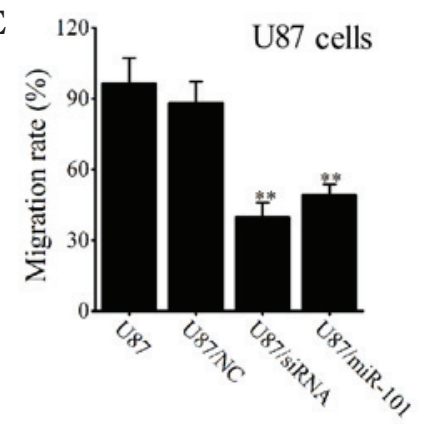

Figure 3. The effect of miR-101 and COX-2 siRNA on proliferation and migration ability of glioma cells. (A and B) Viability of wild type glioma cells and cells transfected with miR-101, COX-2 siRNA or empty vectors was determined by Cell Counting Kit-8 assays. Viability was set at 100\% on day 1. (C-E) Migration ability of WT glioma cells and cells transfected with the miR-101, COX-2 siRNA or empty vectors was determined by Transwell assays. The (C) microscope images (magnification, $\mathrm{x} 4000$ ) and (D and E) statistical analysis indicate that the transfection of either miR-101 or COX-2 siRNA significantly suppresses the cell migration rate in the two glioma cell lines. Data are expressed as the mean \pm standard deviation $(n=3),{ }^{* * *} \mathrm{P}<0.01$ vs. control (wild-type U373/U87 cells). siRNA, small interfering RNA; COX-2, cyclooxygenase-2; WT, wild type; NC, empty vector.

\section{Results}

Elevated COX-2 expression in human glioma tissues and cells. To identify aberrant COX-2 expression in glioma, the COX-2 protein levels in normal and malignant tissues in 33 glioma and adjacent normal tissues were analyzed by western blotting. Representative images (Fig. 1A) demonstrate that COX-2 is significantly overexpressed in glioma tissues when compared with that in normal tissues. Consistent results were obtained in cultured cell lines as shown in Fig. 1B, which revealed that COX-2 was significantly overexpressed in both U373 and U87 glioma cell lines compared with C6 cells. COX-2 overexpression in malignant tissues and cells was confirmed at the mRNA level by RT-qPCR analysis (Fig. 1C and D).

miR-101 downregulation in glioma tissues and cell lines. RT-qPCR results (Fig. 1E) demonstrated that the mean expression of miR-101 was significantly decreased in all glioma cancer tissues when compared with normal tissues $(\mathrm{P}<0.001)$. Similarly, the levels of miR-101 in both U373 and U87 cells were significantly lower than that in C6 cells $(\mathrm{P}<0.001$; Fig. 1F).

Overexpression of miR-101 significantly reduces $C O X-2$ levels in glioma cells. Considering the downregulation of miR-101 levels (Fig. 1E and F) and upregulation of COX-2 expression in human glioma cells and tissues (Fig. 1A-D), we hypothesized that a negative correlation may exist between the intracellular levels of COX-2 and miR-101. To verify this hypothesis, the luciferase reporter system was used to investigate the regulatory function of miR-101 on the expression of COX-2. The results revealed that transfection with miR-101, but not empty vectors [negative control (NC)], significantly reduced the luciferase levels in U373 and U87 cells (Fig. 2A). The results were confirmed by western blot analysis. As shown in Figure 2B, miR-101 transfection markedly downregulated COX-2 expression in both U373 and U87 glioma cells.

Overexpression of miR-101 inhibits cell proliferation and migration of glioma cells. To investigate the effect of 


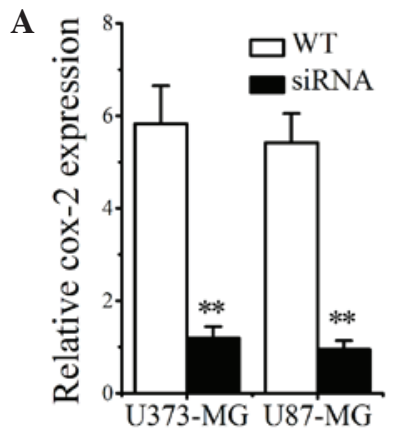

B

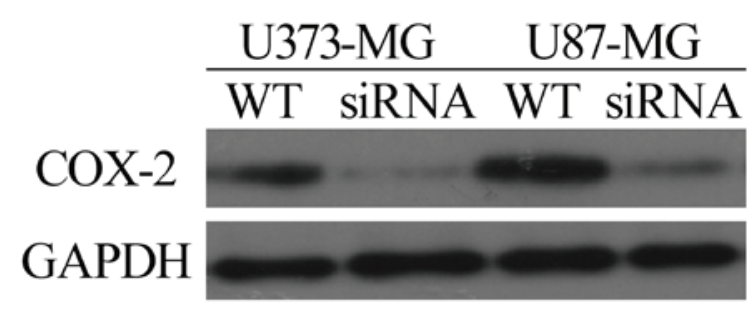

Figure 4. Successful transfection of siRNAs into glioma cells was confirmed by (A) quantitative reverse-transcription polymerase chain reaction and (B) western blotting. Data are expressed as the mean \pm standard deviation $(n=3) .{ }^{* *} \mathrm{P}<0.01$ vs. control. WT, wild type; siRNA, small interfering RNA.
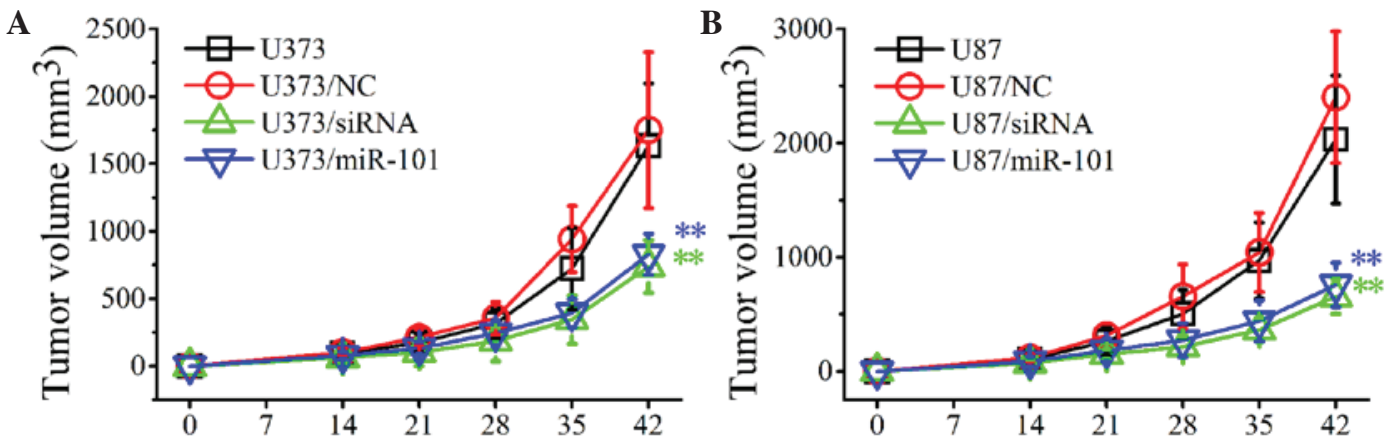

Figure 5. In vivo inhibitory effects of miR-101 and cyclooxygenase-2 siRNA on the growth of established gliomas. (A) U373 and (B) U87 cells were injected subcutaneously into BALB/c nude mice. The development of tumors was recorded for 6 weeks. Data are expressed as the mean \pm standard deviation (n=3). ${ }^{* *} \mathrm{P}<0.01$ vs. control. siRNA, small interfering RNA.

miR-101, cell proliferation was assessed in wild type (WT) and miR-101-overexpressing glioma cells. Cells transfected with empty vectors were used as an NC. Figure $3 \mathrm{~A}$ illustrates that after a 7-day period of proliferation, cell proliferation was lower in the miR-101-transfected group (U373/miR-101) than in the non-transfected (U373) and mock-vehicle groups (U373/NC; P<0.001). Similar results were obtained in U87 cells (Fig. 3B).

Transwell assays were used to measure the effect of miR-101 on tumor cell migration. After $12 \mathrm{~h}$, the number of migrated cells was markedly decreased in miR-101-overexpressing U373 and U87 cells (Fig. 3C) and this effect was also observed after $24 \mathrm{~h}$. After $24 \mathrm{~h}$, the migration rate of U373 (U373/miR-101) and U87 (U87/miR-101) cells was significantly reduced when compared with that of WT and NC-transfected cells $(\mathrm{P}<0.001$; Fig. 3D and E). The results indicate that miR-101 overexpression inhibits cellular proliferation and migration of U373 and U87 glioma cells.

COX-2 interference inhibits cell proliferation and migration of glioma cells. To determine the impact of COX-2 on the proliferation and invasion of glioma cancer cells, glioma cells were transfected with COX-2 siRNAs and the proliferation and invasion abilities were compared between WT and siRNA-transfected glioma cells (U373/siRNA and U87/siRNA groups). The successful transfection of siRNAs into U373 and U87 cells was confirmed by RT-qPCR and western blotting, the results of which revealed that COX-2 mRNA and protein levels were significantly decreased (Fig. 4A and B). The results shown in Fig. 3 suggest that transfection with COX-2 siRNA negatively influences the proliferation (Fig. 3A and B) and invasion (Fig. 3D-F) of human U373 and U87 glioma cells.

Overexpression of miR-101 inhibits the development of established tumors in a localized human glioma xenotransplant model. To investigate the inhibitory effects of miR-101 overexpression on the growth of established tumors, control and miR-101-transfected U373 and U87 cells were injected subcutaneously into BALB/c nude mice. The development of established tumors was monitored every day for 6 weeks. As shown in Fig. 5, the development of solid tumors was first visible at $\sim 14$ days post-inoculation and tumors grew rapidly in WT (U373 and U87) and NC-transfected (U373/NC and U87/NC) groups. By contrast, in the U373/miR-101 and U87/miR-101 groups, the tumor growth was markedly slower and the tumor volume was significantly decreased compared with control groups (Fig. 5A and B). Similar results were obtained when glioma cells were transfected with COX-2 siRNAs. The in vivo experiments indicated that miR-101 overexpression may significantly inhibit tumor growth in vivo and thus may present a useful treatment for glioma.

\section{Discussion}

Gliomas are the most malignant tumors of the central nervous system. Although conventional therapies have significantly advanced in recent years, the prognosis of glioma remains poor (1-3). Understanding of the molecular mechanisms of glioma development has improved and, subsequently, molecular targeted therapy has been proposed for the treatment of 
gliomas $(1,15,27,28)$. Molecular targeted therapy requires the identification of novel and efficient therapeutic targets for the diagnosis and treatment of the disease.

Increasing evidence has demonstrated that up/downregulation of miRNAs is involved in the initiation and progression of various types of malignancy via dysregulation of targeting oncogenes and/or tumor suppressor genes (29,30). Investigation of differentially expressed miRNAs in various cancer types has yielded significant information with regard to carcinogenesis, thus providing potential tumor suppressors for treating malignancies $(14,31,32)$.

miR-101 has been reported to be frequently downregulated in various tumor types, including breast, bladder, gastric, prostate, cervical and liver cancers (33-38). To the best of our knowledge, studies regarding the effect of miR-101 in glioma are limited. In the present study, it was demonstrated that miR-101 functions as an effective tumor suppressor via the repression of COX-2 in gliomas.

COX-2, a key enzyme in the production of prostaglandins, is involved in numerous biological processes that are associated with tumorigenesis, including cell proliferation, differentiation, migration and the regulation of antitumor immunity $(8,11-13)$. The regulation of COX-2 expression in cancer has been the focus of numerous studies (11-14). The results of the present study demonstrated that COX-2 levels were significantly increased in glioma tissues and cell lines. Furthermore, miR-101 overexpression caused downregulation of COX-2 in glioma cells and tissues. Notably, COX-2 interference in glioma cells following siRNA or miR-101 transfection resulted in markedly decreased proliferation and migration rates in vitro. The results also suggest that miR-101 overexpression in both U373 and U87 cells results in significant inhibition of tumor growth in localized glioma xenotransplant models.

To the best of our knowledge, this is the first study to demonstrate that miR-101 downregulation contributes to cell proliferation, migration and invasion in gliomas via upregulation of COX-2 expression. The identification of candidate target genes of miR-101 may aid in elucidating potential carcinogenic mechanisms in human gliomas. In summary, these findings indicate that miR-101 may present a novel potential target that may potentially be exploited for the treatment of glioma.

\section{Acknowledgements}

This study was supported by funds for the modernization of traditional Chinese medicine in Hainan Province (grant no. 2015zy23).

\section{References}

1. Gu X, Wang C, Wang X, Ma G, Li Y, Cui L, Chen Y, Zhao B and Li K: Efficient inhibition of human glioma development by RNA interference-mediated silencing of PAK5. Int J Biol Sci 11: 230-237, 2015.

2. Meyer MA: Malignant gliomas in adults. N Engl J Med 359: 1850; author reply $1850,2008$.

3. Ostrom QT, Gittleman H, Liao P, Rouse C, Chen Y, Dowling J, Wolinsky Y, Kruchko C and Barnholtz-Sloan J: CBTRUS statistical report: Primary brain and central nervous system tumors diagnosed in the United States in 2007-2011. Neuro Oncol 16 (Suppl 4): ivl-iv63, 2014.

4. Huang FY, Lee TW, Chang CH, Chen LC, Hsu WH, Chang CW and Lo JM: Evaluation of (188) Re-labeled PEGylated nanoliposome as a radionuclide therapeutic agent in an orthotopic glioma-bearing rat model. Int J Nanomedicine 10: 463-473, 2015
5. Vredenburgh JJ, Desjardins A, Reardon DA, Peters KB, Herndon JE II, Marcello J, Kirkpatrick JP, Sampson JH, Bailey L, Threatt $\mathrm{S}$, et al: The addition of bevacizumab to standard radiation therapy and temozolomide followed by bevacizumab, temozolomide and irinotecan for newly diagnosed glioblastoma. Clin Cancer Res 17: 4119-4124, 2011.

6. Stupp R, Mason WP, van den Bent MJ, Weller M, Fisher B, Taphoorn MJ, Belanger K, Brandes AA, Marosi C, Bogdahn U, et al: Radiotherapy plus concomitant and adjuvant temozolomide for glioblastoma. N Engl J Med 352: 987-996, 2005.

7. Quick A, Patel D, Hadziahmetovic M, Chakravarti A and Mehta M: Current therapeutic paradigms in glioblastoma. Rev Recent Clin Trials 5: 14-27, 2010.

8. Karavitis $\mathrm{J}$ and Zhang M: COX2 regulation of breast cancer bone metastasis. Oncoimmunology 2: e23129, 2013.

9. Tsujii M and DuBois RN: Alterations in cellular adhesion and apoptosis in epithelial cells overexpressing prostaglandin endoperoxide synthase 2. Cell 83: 493-501, 1995.

10. Howe LR: Inflammation and breast cancer. Cyclooxygenase/prostaglandin signaling and breast cancer. Breast Cancer Res 9: 210,2007.

11. Tyagi A, Agarwal C, Dwyer-Nield LD, Singh RP, Malkinson AM and Agarwal R: Silibinin modulates TNF- $\alpha$ and IFN- $\gamma$ mediated signaling to regulate COX2 and iNOS expression in tumorigenic mouse lung epithelial LM2 cells. Mol Carcinog 51: 832-842, 2012.

12. Martín Sanz P, Hortelano S, Bosca L and Casado M: Cyclooxygenase 2: Understanding the pathophysiological role through genetically altered mouse models. Front Biosci 11: 2876-2888, 2006.

13. Krzystyniak KL: Current strategies for anticancer chemoprevention and chemoprotection. Acta Pol Pharm 59: 473-478, 2002.

14. Farh KK, Grimson A, Jan C, Lewis BP, Johnston WK, Lim LP, Burge CB and Bartel DP: The widespread impact of mammalian MicroRNAs on mRNA repression and evolution. Science 310: 1817-1821, 2005.

15. Yamashita D, Kondo T, Ohue S, Takahashi H, Ishikawa M, Matoba R, Suehiro S, Kohno S, Harada H, Tanaka J and Ohnishi T: MiR-340 suppresses the stem-like cell function of glioma-initiating cells by targeting tissue plasminogen activator. Cancer Res 75: 1123-1133, 2015.

16. Wu D, Zhou Y, Pan H, Zhou J, Fan Y and Qu P: MicroRNA-99a inhibiting cell proliferation, migration and invasion by targeting fibroblast growth factor receptor 3 in bladder cancer. Oncol Lett 7: 1219-1224, 2014.

17. Slaby O, Svoboda M, Fabian P, Smerdova T, Knoflickova D, Bednarikova M, Nenutil R and Vyzula R: Altered expression of miR-21, miR-31, miR-143 and miR-145 is related to clinicopathologic features of colorectal cancer. Oncology 72: 397-402, 2007.

18. Calin GA and Croce CM: MicroRNA signatures in human cancers. Nat Rev Cancer 6: 857-866, 2006.

19. Silber J, Lim DA, Petritsch C, Persson AI, Maunakea AK, Yu M, Vandenberg SR, Ginzinger DG, James CD, Costello JF, et al: MiR-124 and miR-137 inhibit proliferation of glioblastoma multiforme cells and induce differentiation of brain tumor stem cells. BMC Med 6: 14, 2008.

20. Chan JA, Krichevsky AM and Kosik KS: MicroRNA-21 is an antiapoptotic factor in human glioblastoma cells. Cancer Res 65: 6029-6033, 2005.

21. Zhang Y, Chao T, Li R, Liu W, Chen Y, Yan X, Gong Y, Yin B, Liu W, Qiang B, et al: MicroRNA-128 inhibits glioma cells proliferation by targeting transcription factor E2F3a. J Mol Med (Berl) 87: 43-51, 2009

22. Lorimer IA: Regulation of p27Kip1 by miRNA 221/222 in glioblastoma. Cell Cycle 8: 2685, 2009.

23. Lou M and Zhao Y: Satisfactory therapy results of combining nimustine with nicardipine against glioma at advanced stage. J Cancer Res Ther 11: 1030, 2015.

24. Dews M, Homayouni A, Yu D, Murphy D, Sevignani C, Wentzel E, Furth EE, Lee WM, Enders GH, Mendell JT and Thomas-Tikhonenko A: Augmentation of tumor angiogenesis by a Myc-activated microRNA cluster. Nat Genet 38: 1060-1065, 2006.

25. Wu C, Li H, Zhao H, Zhang W, Chen Y, Yue Z, Lu Q, Wan Y, Tian $X$ and Deng A: Potentiating antilymphoma efficacy of chemotherapy using a liposome for integration of CD20 targeting, ultra-violet irradiation polymerizing and controlled drug delivery. Nanoscale Res Lett 9: 447, 2014.

26. Bandrés E, Cubedo E, Agirre X, Malumbres R, Zárate R, Ramirez N, Abajo A, Navarro A, Moreno I, Monzó M and García-Foncillas J: Identification by Real-time PCR of 13 mature microRNAs differentially expressed in colorectal cancer and non-tumoral tissues. Mol Cancer 5: 29, 2006. 
27. Li J, Yen C, Liaw D, Podsypanina K, Bose S, Wang SI, Puc J, Miliaresis C, Rodgers L, McCombie R, et al: PTEN, a putative protein tyrosine phosphatase gene mutated in human brain, breast and prostate cancer. Science 275: 1943-1947, 1997.

28. Hermanson M, Funa K, Hartman M, Claesson-Welsh L, Heldin $\mathrm{CH}$, Westermark B and Nistér M: Platelet-derived growth factor and its receptors in human glioma tissue: Expression of messenger RNA and protein suggests the presence of autocrine and paracrine loops. Cancer Res 52: 3213-3219, 1992.

29. Bartel DP: MicroRNAs: Genomics, biogenesis, mechanism and function. Cell 116: 281-297, 2004.

30. He L and Hannon GJ: MicroRNAs: Small RNAs with a big role in gene regulation. Nat Rev Genet 5: 522-531, 2004

31. Gao J, Li L, Wu M, Liu M, Xie X, Guo J, Tang H and Xie X: MiR-26a inhibits proliferation and migration of breast cancer through repression of MCL-1. PLoS One 8: e65138, 2013.

32. Lin Y, Chen H, Hu Z, Mao Y, Xu X, Zhu Y, Xu X, Wu J, Li S, Mao Q, et al: MiR-26a inhibits proliferation and motility in bladder cancer by targeting HMGA1. FEBS Lett 587: 2467-2473, 2013

33. Deng M, Tang HL, Lu XH, Liu MY, Lu XM, Gu YX, Liu JF and He ZM: MiR-26a suppresses tumor growth and metastasis by targeting FGF9 in gastric cancer. PLoS One 8: e72662, 2013.

34. Zhao S, Ye X, Xiao L, Lian X, Feng Y, Li F and Li L: MiR-26a inhibits prostate cancer progression by repression of Wnt5a. Tumour Biol 35: 9725-9733, 2014.
35. Verghese ET, Drury R, Green CA, Holliday DL, Lu X, Nash C, Speirs V, Thorne JL, Thygesen HH, Zougman A, et al: MiR-26b is down-regulated in carcinoma-associated fibroblasts from ER-positive breast cancers leading to enhanced cell migration and invasion. J Pathol 231: 388-399, 2013.

36. Liang X, Liu Y, Zeng L, Yu C, Hu Z, Zhou Q and Yang Z: MiR-101 inhibits the G1-to-S phase transition of cervical cancer cells by targeting Fos. Int J Gynecol Cancer 24: 1165-1172, 2014

37. Sheng Y, Li J, Zou C, Wang S, Cao Y, Zhang J, Huang A and Tang H: Downregulation of miR-101-3p by hepatitis B virus promotes proliferation and migration of hepatocellular carcinoma cells by targeting Rab5a. Arch Virol 159: 2397-2410, 2014.

38. Edge SB, Sobin LH, Page DL, Gospodarowicz MK, Greene FL and Winchester DP: Re: Colon cancer survival rates with the new American Joint Committee on Cancer sixth edition staging. J Natl Cancer Inst 97: 463-464, 2005. 